\title{
Increased use of high-flow nasal oxygen during bronchoscopy
}

To the Editor:

High-flow nasal cannula (HFNC) oxygen therapy is increasingly applied in adult patients with acute respiratory failure (ARF) [1-4]. It delivers heated and humidified air providing higher and more expected gas flow rates and fraction inspired oxygen $\left(\mathrm{FiO}_{2}\right)$ than traditional oxygen therapy [2].

We read carefully the article by LA COMBE et al. [1] and congratulate the authors on their study. There are, however, some limitations to the study that need considering.

First, during bronchoscopy, arterial oxygen tension $\left(\mathrm{PaO}_{2}\right)$ can decrease approximately $20 \mathrm{mmHg}$ and the most critical reduction usually occurs, when bronchoalveolar lavage (BAL) is performed $[3,4]$.

Second, in the procedure failure group, median baseline $\mathrm{PaO}_{2}$ was $68 \mathrm{mmHg}$ but, according to the American Thoracic Society recommendations, bronchoscopy and BAL should not be carried out in patients with hypoxaemia that cannot be corrected to a $\mathrm{PaO}_{2}$ of at least $75 \mathrm{mmHg}$ or to an arterial oxygen saturation of $90 \%$ with supplemental oxygen $[3,5]$.

Third, to better identify patients at higher risk of procedure failure and therefore with a poorer prognosis, it would be interesting to know the diagnosis at the time of admission in the intensive care unit.

Fourth, in the procedure failure group, all the baseline arterial blood gas values were lower than in the other group, except for the median arterial carbon dioxide tension, suggesting that maybe parameters were not sufficiently adjusted, such as the oxygen flow.

In conclusion, HFNC is easy to perform and is well tolerated [1, 3], which may lead to increasing its use in the future.

@ERSpublications

The patient should be clinically stable before performing bronchoscopy http://ow.ly/4mIK0W

Pedro Silva Santos ${ }^{1}$, Cristiana Cruz $^{1}$ and Antonio M. Esquinas ${ }^{2}$

${ }^{1}$ Pulmonology Unit, Centro Hospitalar e Universitário de Coimbra - Hospitais da Universidade de Coimbra, Coimbra, Portugal. ${ }^{2}$ Internsive Care Unit, Hospital Morales Meseguer, Múrcia, Spain.

Correspondence: Pedro Silva Santos, Pulmonology Unit, Centro Hospitalar e Universitário de Coimbra - Hospitais da Universidade de Coimbra, Coimbra, Portugal. E-mail: pedrorssantos@gmail.com

Received: March 012016 | Accepted: March 122016

Conflict of interest: None declared.

\section{References}

1 La Combe B, Messika J, Labbé V, et al. High-flow nasal oxygen for bronchoalveolar lavage in acute respiratory failure patients. Eur Respir J 2016; 47: 1283-1286.

2 Sotello D, Rivas M, Mulkey Z, et al. High-flow nasal canula oxygen in adult patients: a narrative review. Am J Med Sci 2015; 349: 179-185.

3 Miyagi K, Haranaga S, Higa F, et al. Implementation of bronchoalveolar lavage using a high-flow cannula in five cases of acute respiratory failure. Respir Inv 2014; 52: 310-314.

4 Lucangelo U, Vassallo FG, Marras E, et al. High-flow nasal interface improves oxygenation in patients undergiong bronchoscopy. Crit Care Res Pract 2012; 2012: 506382.

5 Goldstein RA, Rohatgi PK, Bergofsky EH, et al. Clinical role of bronchoalveolar lavage in adults with pulmonary disease. Am Rev Respir Dis 1990; 142: 481-486. 